\title{
Modernización de CONACEM
}

\author{
Modernizing 'CONACEM' - Autonomous Chilean Corporation of Certification \\ of Medical Specialities
}

La Corporación Nacional Autónoma de Certificación de Especialidades Médicas: CONACEM nace en 1984 frente a la necesidad que una Institución autónoma, independiente, del más alto nivel académico y técnico se hiciera cargo de la Certificación de Especialidades Médicas en Chile. Para su constitución concurren las Instituciones Médicas más importantes e influyentes del país, como son la Asociación de Facultades de Medicina de Chile (ASOFAMECH), la Asociación de Sociedades Científicas Médicas de Chile (ASOCIMED), la Academia Chilena de Medicina y el Colegio Médico de Chile. Hasta ese momento los únicos especialistas con título universitario eran aquellos formados a través de un programa universitario, cuyos docentes podian no tener una especialidad reconocida tan claramente como sus propios alumnos.

La primera tarea de CONACEM fue validarse como la Institución Certificadora, lo cual logró en el transcurso de los años, llegando a tener el prestigio de una marca reconocida. Actualmente CONACEM está constituida por un Directorio de 13 miembros que representan a las Instituciones que la componen: Academia de Medicina (1), ASOFAMECH (4), ASOCIMED (4) y Colegio Médico de Chile (4). Cuenta con un Secretario Ejecutivo que le da continuidad a su accionar y una pequeña planta administrativa. El Directorio es apoyado por 58 Comités de Especialidades con 7 miembros cada uno, más de 150 profesores examinadores. Lo que significa más de 570 médicos participando de manera ad honorem al objetivo de esta Corporación. CONACEM se caracteriza por ser una institución representativa de la medicina chilena, con una enorme experiencia en certificación de especialistas, reconocida a todo nivel, de gran mistica representada en sus médicos participantes, transparente, independiente y sin fines de lucro. A diciembre de 2016 ha efectuado 13.506 certificaciones de especialistas. Está centrada en la certificación de especialistas médicos y en la definición y reconocimiento de nuevas especialidades médicas. Tempranamente se confeccionó los requisitos generales para la certificación de especialidades, definiendo las especialidades a certificar, ya fuesen primarias o derivadas y los requisitos específicos de cada una de ellas. Actualmente para los médicos la certificación de especialidad es absolutamente necesaria, tanto para el sistema público como privado de salud, a pesar de ello para CONACEM constituye un acto absolutamente voluntario.

En febrero del año 2004 se dicta la ley 19.937 de Autoridad Sanitaria que establece un sistema de certificación de especialistas y encomienda a los Ministerios de Salud y de Educación para definir las entidades certificadoras y las condiciones de su funcionamiento y autorización.

El 6 de noviembre de 2008 se dicta el Decreto Supremo $N^{\circ} 57$ sobre Reglamento de Certificación de las Especialidades y Subespecialidades de los Prestadores Individuales de Salud y de la Entidades que la otorgan el cual establece 24 especialidades y 18 subespecialidades, dispone dictar Normas Técnicas Operativas por parte del Ministerio de Salud, dispone los requisitos para la autorización de la entidades certificadoras, define que la vigencia de la certificación fluctuará entre 5 y 10 años, establece que las universidades podrán certificar aquellas especialidades con programas acreditados, se crea un 'Registro Público de Prestadores Individuales' a cargo de la Intendencia de Prestadores de Salud.

El 5 de febrero de 2013 se dicta el Decreto Supremo $N^{\circ}$ 8, que deroga el Decreto Supremo $N^{\circ}$ 57, el cual define 52 Especialidades Médicas Primarias y Derivadas (Subespecialidades) y define también los criterios para incorporar nuevas especialidades al sistema de certificación. 
Inicialmente las certificaciones vigentes el año 2008 serían válidas por un plazo de 7 años, modificaciones posteriores han establecido que su duración se extenderá hasta el 31 de diciembre de 2019.

La Resolución Exenta $N^{\circ} 399$ del 11 de febrero de 2014 del Ministerio de Salud autoriza a CONACEM como entidad Certificadora de Especialidades Médicas. La autorización como entidad certificadora fue hecha inicialmente para 24 especialidades primarias y derivadas, actualmente estamos llegando a las 52.

Ha habido dos situaciones que se han transformado en dos grandes desafios para CONACEM. En primer lugar la solicitud de 'Certificación por formación en el extranjero'. El año 2015 tuvimos 122 solicitudes por esta vía, de las cuales el $56 \%$ eran extranjeros y el $44 \%$ eran chilenos; al 30 de septiembre de 2017 las solicitudes eran 929 (93\% extranjeros y 7\% chilenos). Recientemente se publicó la ley 20.985, la cual permite que médicos extranjeros con certificado de especialidad de su país, puedan solicitar a CONACEM el reconocimiento de su especialidad sin tener el título profesional de médico cirujano válido para ejercer en Chile. Están eximidos de presentar el documento habilitante. La certificación es solo para la especialidad o subespecialidad solicitada y solo para el Sector Público. Esta situación ha provocado un aumento exponencial de solicitudes que es un desafio no solo por el aumento del número de postulantes, sino por la necesidad de suplir, aunque sea solo parcialmente, la falta del examen habilitante de médico cirujano.

El segundo desafio es la 'recertificación de especialistas'. La recertificación en una especialidad médica significa en esencia refrendar la certificación existente, de modo que las constataciones de idoneidad de ese reconocimiento inicial mantengan su valor y actualidad. Sus fundamentos son múltiples y están debidamente justificados. Desde agosto del año 2008 CONACEM otorga el título de especialista con fecha de caducidad a los 10 años y con recertificación cada 7 años. En este nuevo régimen hay alrededor de 3.000 certificaciones entregadas desde agosto de 2018, las cuales deben comenzar con el proceso de recertificación. A la situación previamente descrita es necesario agregar que de acuerdo a la legislación vigente existe alrededor de 20.000 especialistas con vencimiento de su especialidad el 31 de diciembre de 2019, los cuales deberían someterse al proceso de recertificación o renovación de la especialidad.

Ambas situaciones plantean a CONACEM grandes desafios de modernización, profesionalización y perfeccionamiento. Debemos efectuar nuestro trabajo de evaluación en un plazo prudente que debería fluctuar entre 12 y 18 meses.

En el caso de la 'evaluación por formación en el extranjero' cada una de las etapas debe ser cumplida en plazos acotados: revisión de antecedentes por los diferentes comités, el examen teórico y luego el examen práctico. La modalidad más frecuente del examen teórico es una prueba de múltiple elección, que se toma dos veces al año, para aprobarlo se requiere un $65 \%$ de preguntas correctas. Para la correcta confección de las preguntas que reflejen los aspectos técnicos y conocimientos mínimos a evaluar, la corrección de las pruebas y el análisis de los resultados, es necesario contar con un equipo de apoyo docente especializado permanente que nos esté colaborando. Para la evaluación práctica de acuerdo a la especialidad, se debe escoger la mejor manera de lograrlo, quizás en muchas especialidades seguirá siendo un examen al lado del enfermo o escogeremos otro como el Examen Clínico Estructurado Objetivo (OSCE: Objetive Structured Clinical Examination), diseñado para evaluar el desempeño de habilidades clínicas y las competencias en habilidades tales como la comunicación, el examen clínico, procedimientos, prescripción médica, evaluación de imágenes e interpretación de resultados. Se logra mediante un circuito de estaciones cortas, en que cada candidato es examinado individualmente por uno o dos examinadores imparciales de manera real o simulada, sin poner en riesgo la salud de los pacientes, obteniendo una nota por cada paso, haciendo la evaluación de habilidades clínicas más objetiva. Lo anterior lleva aparejada ciertas preguntas, pensando que la aprobación teórica alcanza al 50\% de los postulantes: ¿podremos tomar el examen práctico con el sistema que tenemos, con profesores ad honorem o deberemos establecer un sistema de honorarios para nuestros profesores?; ¿cuál es el valor razonable a cancelar por cada examen práctico?; ¿el pago será de manera directa o a través de instituciones en convenio?; ¿nos obligará o no a aumentar nuestros aranceles? 
En el caso de la recertificación, ya tenemos un reglamento que establece los requisitos generales y un sistema de créditos, que para aprobarla se requiere un mínimo de 100 puntos repartidos en cuatro actividades: asistenciales, académicas, de educación continua y otras. La enorme tarea nos obliga a comenzar la recertificación este año 2018, para ello se requiere constituir un equipo destinado a esta actividad a la brevedad, de tal manera que en agosto del año 2018 oficialmente comencemos el proceso de recertificación. Como dificultad carecemos de un 'Reglamento de Recertificación o de Renovación de la Certificación' por parte del Ministerio de Salud, el cual deberá establecer quienes tienen derecho a ella, establecer sus grandes lineamientos y definir los plazos para realizarla. Parece prudente la gradualidad en la realización de la Recertificación, para evitar una situación de atochamiento de muy difícil solución.

En resumen debemos adaptarnos al nuevo escenario en el que estamos inmersos, analizar las diferentes proposiciones esbozadas y pronunciarnos sobre los caminos a seguir de tal manera de mantenernos como la institución responsable de la Certificación y de la Recertificación en Chile, que es lo más conveniente para la Medicina Chilena.

\section{Lorenzo Naranjo Tapia}

Presidente,

Corporación Nacional Autónoma de Certificación de Especialidades Médicas,

Email:conacem@mcloud.cl

\section{Bibliografía}

1.- LÓPEZ J M, HERVÉ L. Corporación Nacional Autónoma de Certificación de Especialidades Médicas (1984-2015). Talleres de Gráfica LOM. Santiago de Chile. 1ª Edición. Diciembre 2016 (256 págs.) ISBN 978-956-9920-00-4 